\title{
Long-term monitoring of patients with infantile-onset Pompe disease on enzyme replacement therapy using a urinary glucose tetrasaccharide biomarker
}

\author{
Sarah P. Young, PhD ${ }^{I}$, Haoyue Zhang, PhD $D^{I}$, Deyanira Corzo, $M D^{2}$, Beth L. Thurberg, MD, PhD', \\ Deeksha Bali, PhD ${ }^{I}$, Priya S. Kishnani, $M D^{I}$, and David S. Millington, PhD
}

\begin{abstract}
Purpose: To investigate the correlation of the urinary glucose tetrasaccharide, Glc $\alpha 1-6 \mathrm{Glc} \alpha 1-4 \mathrm{Glc} \alpha 1-4 \mathrm{Glc},\left(\mathrm{Glc}_{4}\right)$ with skeletal muscle glycogen content and the long-term clinical response to enzyme replacement therapy with recombinant human acid alpha glucosidase in infantile Pompe disease. Methods: Eighteen patients, $\leq 6$ months old, were enrolled in a clinical trial of enzyme replacement therapy for up to 142 weeks. Urinary $\mathrm{Glc}_{4}$, skeletal muscle glycogen, and other clinical and laboratory assessments were made at baseline and at regular intervals. Urinary $\mathrm{Glc}_{4}$ was determined using an isotope-dilution tandem mass spectrometric assay. The clinical response to treatment was defined according to the motor function response. Trends in urinary $\mathrm{Glc}_{4}$ were correlated with the clinical response and compared with serum enzyme markers of skeletal muscle damage, creatine kinase, aspartate aminotransferase, and alanine aminotransferase. Results: Urinary $\mathrm{Glc}_{4}$, in contrast to the serum markers, correlated closely with skeletal muscle glycogen content and with the clinical response. Patients with the best response to treatment maintained the lowest levels of $\mathrm{Glc}_{4}$ throughout the trial. Conclusion: The results from this study support the use of urinary $\mathrm{Glc}_{4}$ for monitoring patients with infantile-onset Pompe disease on therapy. Genet Med 2009:11(7):536-541.
\end{abstract}

Key Words: Pompe disease, enzyme replacement therapy, glucose tetrasaccharide, biomarker, tandem mass spectrometry

Oompe disease is a glycogen storage disease caused by a deficiency of the lysosomal enzyme acid alpha glucosidase (GAA). ${ }^{1}$ The disease primarily affects the function of cardiac,

\footnotetext{
From the ${ }^{1}$ Division of Medical Genetics, Department of Pediatrics, Duke University Medical Center, Durham, North Carolina; and ${ }^{2}$ Genzyme Corporation, Cambridge, Massachusetts.
}

Sarah P. Young, PhD, Biochemical Genetics Laboratory, 801 Capitola Drive, Suite 6, Durham, NC 27713. E-mail: young116@mc.duke.edu.

Deyanira Corzo is currently at Millennium Pharmaceuticals Inc., Cambridge, Massachusetts.

Supplemental digital content is available for this article. Direct URL citations appear in the printed text and are provided in the HTML and PDF versions of this article on the journal's Web site (www.geneticsinmedicine.org).

Disclosure: The clinical trial with rhGAA has been supported by a grant from Genzyme Corporation at the various sites that patients were treated. S.Y., D.B., P.S.K., and D.M. have received research/grant support from Genzyme Corporation; P.S.K. is a member of the Pompe Disease Advisory Board for Genzyme Corporation. rhGAA, in the form of Genzyme's product, Myozyme $^{\mathrm{TM}}$, has now been approved by the US FDA and the European Union as therapy for Pompe disease. Duke University and inventors for the method of treatment and predecessors of the cell lines used to generate the enzyme (rhGAA) used in this clinical trial will receive royalty payments pursuant to the University's Policy on Inventions, Patents and Technology Transfer.

Submitted for publication October 16, 2008

Accepted for publication March 31, 2009.

Published online ahead of print June 10, 2009.

DOI: $10.1097 /$ GIM.0b013e3181a87867 smooth, and skeletal muscles, where lysosomal glycogen accumulation is most evident. The age of onset and progression of Pompe disease varies widely. Patients with the early-onset (infantile) form of the disease are characterized by very low residual enzyme activity, hypotonia, rapidly progressive muscle myopathy, and cardiomyopathy.

Pompe disease is one of several lysosomal storage disorders for which an enzyme replacement therapy (ERT) has been developed. Clinical trials of ERT with recombinant, human GAA (rhGAA) in infantile populations have reported improved outcomes for treated patients when compared with the natural course of the disease. ${ }^{2-8}$ These included increased ventilatorfree survival, improvement in cardiac hypertrophy, and gains in motor function. The cardiac response to treatment was significant and independent of the stage and extent of muscle disease, whereas the motor function response was more variable and ranged from independent ambulation to minimal motor gains with respiratory insufficiency. A histologic study of quadriceps biopsies from eight infantile patients in a Phase II clinical trial of ERT with rhGAA suggested several factors may influence the motor function response to treatment. ${ }^{9}$ The extent of glycogen accumulation and muscle damage and the age of the patient at the start of treatment correlated with the histologic response. In turn, the extent of glycogen clearance from muscle correlated with the clinical response to treatment. Ongoing studies are examining the impact of other factors, such as the type of mutation and the development of antibodies to the infused enzyme on the clinical outcome of ERT.

Food and Drug Administration approval of rhGAA (Myozyme $^{\mathbb{B}}$ ) was granted in April 2006 and guidelines for the diagnosis and treatment of Pompe disease were published. ${ }^{10}$ Monitoring the clinical, histologic, immunologic, and biochemical responses to treatment is important in trying to understand and predict the outcome of therapy. As mentioned above, histologic studies of muscle biopsies to assess the disease burden at the start of treatment and to monitor the clearance of the glycogen over time provided valuable information on the response to treatment. However, muscle biopsies are invasive procedures and there is an increased risk from anesthesia in this patient population. The glucose tetrasaccharide, Glc $\alpha 1-6 \mathrm{Glc} \alpha 1-$ $4 \mathrm{Glc} \alpha 1-4 \mathrm{Glc}\left(\mathrm{Glc}_{4}\right)$ is a limit dextrin of glycogen. ${ }^{11,12}$ It is normally excreted in the urine at low concentrations and its urinary excretion is elevated in patients with Pompe disease. We have previously proposed that urinary $\mathrm{Glc}_{4}$ may have value as a noninvasive biomarker of glycogen storage for monitoring the response to ERT. We showed that urinary and plasma $\mathrm{Glc}_{4}$ levels correlated with the motor response to treatment over 52 weeks for 11 infantile patients enrolled in Phase I/II clinical trials. ${ }^{13}$ We now report on a more extensive study of this biomarker from a Phase II/III clinical trial involving a different cohort of patients $(n=18)$. Patients enrolled on this trial were diagnosed and started on therapy at or before the age of 6 
months. The safety and efficacy of ERT over the first year of treatment has previously been published by Kishnani et al. ${ }^{4} \mathrm{We}$ describe the correlation of urinary $\mathrm{Glc}_{4}$ with the muscle glycogen content and with the motor function response to treatment over 2-3 years. We also compare the value of $\mathrm{Glc}_{4}$ as a biomarker for monitoring the efficacy of treatment with serum enzyme markers of muscle damage.

\section{MATERIALS AND METHODS}

\section{Materials}

$\mathrm{Glc}_{4}$ standard was purchased from Glycorex AB (Lund, Sweden). $\left[{ }^{13} \mathrm{C}_{6}\right]$-labeled glucose tetrasaccharide internal standard was synthesized as previously described. ${ }^{14} \mathrm{D}_{3}$-creatinine was purchased from Cambridge Isotopes (Andover, MA) and creatinine standards, sodium cyanoborohydride, butyl 4-aminobenzoate, and glacial acetic acid from Sigma-Aldrich (St. Louis, MO). All solvents were high performance liquid chromatography grade (VWR, West Chester, PA). Sep-Pak ${ }^{\circledR}$ Vac C18 cartridges $(100 \mathrm{mg})$ were from Waters Corporation (Milford, MA). Deionized water $\left(\mathrm{DI}-\mathrm{H}_{2} \mathrm{O}\right)$ was prepared in-house.

\section{Study design and subjects}

A description of the design, safety, and clinical efficacy for the first year of this open-label, multicenter, international trial of ERT with Chinese hamster ovary-derived recombinant rhGAA has previously been published. ${ }^{4}$ The trial was extended for up to an additional 90 weeks and the results from the extension phase have not yet been reported. Briefly, 18 patients with infantile Pompe disease enrolled in the study met the inclusion criteria of minimal GAA activity in skin fibroblasts, cardiac hypertrophy, ventilator-free status and were $\leq 6$ months of age, corrected for gestational age at the start of ERT. Urine samples for $\mathrm{Glc}_{4}$ analysis were collected at 0,4 , and 12 weeks and then at quarterly intervals over 2-3 years of ERT, until the end of the study in June 2006. The number of urine collections depended upon the time of enrollment in the study and survival for each patient. By the end of the study, 1 patient had samples collected up to 52 weeks, 3 patients up to 90 weeks, 4 patients up to 104 weeks, 5 patients up to 116 weeks, 3 patients up to 130 weeks, and 2 patients up to 142 weeks. Informed consent for these studies was obtained after protocols approved by Institutional Review Boards or Independent Ethics Committees at the participating centers.

\section{$\mathrm{Glc}_{4}$ analysis in urine}

$\mathrm{Glc}_{4}$ was determined using a method that measured the total hexose tetrasaccharide $\left(\mathrm{Hex}_{4}\right)$ fraction in urine. $\mathrm{Glc}_{4}$ is the predominant hexose tetrasaccharide isomer in urine, and represents more than $90 \%$ of the total hexose tetrasaccharide fraction in both control and patient samples (unpublished observations). Hence, measurement of the total $\mathrm{Hex}_{4}$ fraction is a reasonable assessment of the $\mathrm{Glc}_{4}$ concentration. For the purposes of this article, the biomarker in urine will be referred to as $\mathrm{Glc}_{4}$. The method used was based on a published procedure that uses liquid chromatography-stable isotope dilution tandem mass spectrometry ${ }^{14}$ and was modified as follows. Analyses were performed on an Acquity UPLC coupled with a Quattro Micro tandem mass spectrometer (Waters, Milford, MA). Ten microliters of the $p$-butyl aminobenzoate-derivatized neutral oligosaccharide preparation, reconstituted in 80:20 (v/v) methanol: DI- $\mathrm{H}_{2} \mathrm{O}$, was injected onto a BEH C18 $2.1 \times 50 \mathrm{~mm}, 1.7 \mu \mathrm{m}$ Acquity column (Waters, Milford, MA). The mobile phase was 80:20 (v/v) methanol:DI- $\mathrm{H}_{2} \mathrm{O}$, and the flow rate was $400 \mu \mathrm{L} /$ minute. The column eluant was directly infused into the mass spectrometer. $\mathrm{Glc}_{4}$ was detected by monitoring the transition of $\mathrm{m} / \mathrm{z} 866$ to 509 and the internal standard by monitoring the transition of $\mathrm{m} / \mathrm{z} 872$ to 548 . Total analysis time was 1.2 minutes. The signal intensity ratio of $\mathrm{Glc}_{4}$ to that of the internal standard was converted to a concentration using a calibration curve. Urinary $\mathrm{Glc}_{4}$ was determined relative to creatinine values, expressed as $\mathrm{mmol} / \mathrm{mol}$ creatinine $(\mathrm{CN})$, and compared with age-matched control ranges.

Creatinine assays in the same urine specimens were also performed by isotope-dilution tandem mass spectrometry. Briefly, urine was centrifuged at 15,000 rpm for 5 minutes and the supernatant liquid was mixed with an equal volume of 3.2 $\mathrm{mM} \mathrm{d}_{3}$-creatinine solution. Two microliters of the mix was added to $200 \mu \mathrm{L} 10 \mathrm{mM}$ ammonium acetate solution in 65:35 (v/v) acetonitrile:DI- $\mathrm{H}_{2} \mathrm{O}$ in a 96 well plate. Samples were analyzed on a Quattro Micro (Waters Corp, Milford, MA) with an Agilent 1100 LC-pump (Agilent, Santa Clara, CA) and PAL CTC autoinjector (Leap Technologies, Carrboro, NC) by direct infusion, monitoring the transitions of $\mathrm{m} / \mathrm{z} 114$ to 44 for creatinine and $\mathrm{m} / \mathrm{z} 117$ to 47 for $\mathrm{d}_{3}$-creatinine. Ten millimolar ammonium acetate solution in 65:35 (v/v) acetonitrile:DI- $\mathrm{H}_{2} \mathrm{O}$ was used as the mobile phase. The ratio of the signal intensity of creatinine to that of its internal standard was converted to concentration using a calibration curve.

\section{Muscle glycogen determination}

Muscle glycogen content was measured by histomorphometry in quadriceps biopsies at 0,12 , and 52 weeks of ERT. This method of glycogen quantification has been shown to tightly correlate with the biochemical assessment of glycogen levels in preclinical studies ${ }^{15}$ and provides additional information on ultrastructural cellular repair after treatment. The data on the biochemical assessment of glycogen content in these samples were previously reported by Kishnani et al. ${ }^{4}$ as the percentage change from baseline to Week 52. Briefly, samples were prepared for high-resolution light microscopy according to the procedures described by Lynch et al. ${ }^{16}$ Biopsy tissues for light microscopy were placed directly into fixative consisting of $3 \%$ glutaraldehyde in $0.2 \%$ cacodylate buffer, and embedded in epon. The sections were cut at $1 \mu \mathrm{m}$ on a Leica Ultracut E ultramicrotome (Leica Instruments $\mathrm{GmbH}$, Heidelberger, Germany) and placed onto adhesion-coated slides. The slides were placed in water, $1 \%$ periodic acid, rinsed in water, placed into Schiff's reagent (Surgipath, Richmond, IL), and rinsed again in water. The sections were then counterstained in a 1:10 diluted Richardson's stain and rinsed in water. Slides were dried over night in a $60^{\circ} \mathrm{C}$ oven and cover slipped with mounting media. This methodology results in purple staining of well-preserved glycogen against a light blue background. Up to 10 blocks were processed per sample-time point for each patient to accurately represent the distribution of glycogen across the entire specimen. One slide from each block was analyzed by computerassisted morphometry (MetaMorph ${ }^{\circledR}$ Imaging and Analysis Software, Version 4.6, MDS Analytical Technologies, Sunnyvale, CA) as described previously 9 to obtain the percentage of tissue area occupied by glycogen. The values obtained were then combined to obtain an average value and standard deviation for each patient-time point.

\section{Skeletal muscle enzyme measurements}

Serum creatine kinase (CK), aspartate aminotransferase (AST), and alanine aminotransferase (ALT) were determined using standard methods by a central laboratory at $0,4,8$, and 12 weeks and then at quarterly intervals for up to 142 weeks. 


\section{Statistical analyses}

Urinary $\mathrm{Glc}_{4}$ levels and plasma markers of muscle damage were compared between different patient groups and with control values using the Student $t$ test with GraphPad Prism 3 software with Welch's correction for unequal variances where necessary. Statistical significance was defined as $P$ values $<$ 0.05 . The coefficient of determination $\left(r^{2}\right.$ value $)$ was calculated from the Pearson correlation coefficient $(r)$ with GraphPad Prism 3 software and used to assess the correlation between urinary $\mathrm{Glc}_{4}$ and muscle glycogen content.

\section{RESULTS}

\section{Patient responses to enzyme replacement therapy}

For the purposes of this study, patients were classified into three distinct groups according to their motor function response at 52 weeks and by the end of the extension phase of the trial (Table 1). The patient identifiers used in Table 1 correspond to those in an earlier publication. ${ }^{4}$

Group 1 patients ( 7 of 18) were those who had both the best motor function response in the initial phase and sustained clinical improvements by the end of the extension phase of the trial. At 52 weeks, six of these patients had attained the motor milestones of walking (Patients $\mathrm{B}, \mathrm{F}, \mathrm{G}, \mathrm{H}, \mathrm{N}$, and $\mathrm{O}$ ); one was standing (Patient I) and all were ventilator free. By the end of

Table 1. Summary of motor function response to ERT

\begin{tabular}{ccc}
\hline & Age at first & Motor gains \\
infusion (mo) & at 52 wk & $\begin{array}{c}\text { Motor gains by end of } \\
\text { extension phase } \\
\text { of study }\end{array}$ \\
\hline
\end{tabular}

Group 1

B

F

G

$\mathrm{H}$

$\mathrm{N}$

$\mathrm{O}$

I

\section{0}

6.9

4.3

5.3

1.2

6.9

6.4

Group 2

$\mathrm{C}$

$\mathrm{J}$

K

$\mathrm{L}$

$\mathrm{M}$

Q

Group 3

\begin{tabular}{llll} 
A & 5.0 & No gains & Deceased \\
$\mathrm{D}$ & 5.7 & No gains & Deceased \\
$\mathrm{E}$ & 5.9 & No gains & No gains \\
$\mathrm{P}$ & 6.2 & No gains & No gains \\
$\mathrm{R}$ & 2.1 & No gains & No gains \\
\hline
\end{tabular}

the trial, corresponding to 104-130 weeks on ERT, all seven patients were walking independently and were ventilator free.

Group 2 patients ( 6 of 18 ) were those who made measurable motor gains by 52 weeks on ERT, but did not make further gains or suffered a clinical decline in the extension phase. By 52 weeks, three of these patients were sitting (Patients J, K, and Q), two were standing (Patients $\mathrm{L}$ and $\mathrm{M}$ ), and one was walking (Patient $\mathrm{C}$ ). Two of these patients ( $\mathrm{J}$ and $\mathrm{K}$ ) made no further progress on completion of 116 weeks on ERT, and although they were sitting independently, they had no functional use of their legs. The remaining four patients $(\mathrm{C}, \mathrm{L}, \mathrm{M}$, and $\mathrm{Q})$ became invasive ventilator dependent during the extension phase of the trial and exhibited loss of previously acquired milestones. Three of these patients died before the conclusion of the trial $(\mathrm{C}, \mathrm{L}$, and Q).

Group 3 patients (5 of 18 ) were those who failed to gain motor milestones at 52 weeks or by the end of the extension phase of the study and became invasive ventilator dependent between 12 and 60 weeks of ERT. Two of these patients (A and D) died before the conclusion of the extension phase of the study.

In summary, at the end of initial phase of the trial ( 52 weeks) all 18 patients were alive. By the end of the Extension Phase 5 were deceased, including three who had made some motor gains during the initial phase.

\section{Comparison of urinary $\mathrm{Glc}_{4}$ concentrations with muscle glycogen content}

Urinary $\mathrm{Glc}_{4}$ levels were positively correlated with the glycogen content at 0,12 , and 52 weeks $\left(r^{2}=0.43,0.47\right.$, and 0.51 , respectively, $[P<0.01]$; Fig. $1, \mathrm{~A}-\mathrm{C})$. At baseline, urinary $\mathrm{Glc}_{4}$ data were available for four of the five patients in Group 3 (Patients A, D, E, and P) and these patients had the highest basal levels of both glycogen and urinary $\mathrm{Glc}_{4}$ (Fig. 1A). Baseline values were lower for patients in Groups 1 and 2 with the exception of Patient G in Group 1 and Patient Q in Group 2, both of whom also had high values. By 52 weeks of ERT, all of the Group 3 patients had significantly higher glycogen content and urinary $\mathrm{Glc}_{4}$ concentrations than those in the other groups (Fig. 1C).

\section{Correlation of urinary $\mathrm{Glc}_{4}$ concentrations with the motor function response to ERT}

The change in mean $\mathrm{Glc}_{4}$ concentration for the three groups from $0-116$ weeks ERT is shown in Figure 2. There were insufficient data points to compare groups beyond 116 weeks. Graphs of $\mathrm{Glc}_{4}$ trends and glycogen levels for each patient are provided in Supplemental Digital Content 1, http://links.lww.com/A1141; Supplemental Digital Content 2, http://links.lww.com/A1142; and Supplemental Digital Content 3, http://links.lww.com/A1143. The urinary $\mathrm{Glc}_{4}$ levels were elevated at baseline (mean $\pm \mathrm{SD}$ : $38 \pm 11$; min-max: 23-63; age-matched controls: $<19 \mathrm{mmol} /$ $\mathrm{mol} \mathrm{CN}$ ) for all the patients from whom specimens were available (16 of 18). The mean basal $\mathrm{Glc}_{4}$ level for Group 3 patients (mean $\pm \mathrm{SD}: 49 \pm 8 \mathrm{mmol} / \mathrm{mol} \mathrm{CN}, n=4$ ) was significantly greater than the combined mean for Groups 1 and $2(35 \pm 10$ $\mathrm{mmol} / \mathrm{mol} \mathrm{CN}, n=12, P<0.05)$. There was a significant decrease in $\mathrm{Glc}_{4}$ levels after 4 weeks on ERT $(P<0.05$, paired Student $t$ test) regardless of the long-term motor function response, with the exception of one patient (Patient P). The value at 4 weeks of ERT was typically the minimum value observed in each patient, and in the best responders it was within or close to the upper limit of the normal age-matched control range. 


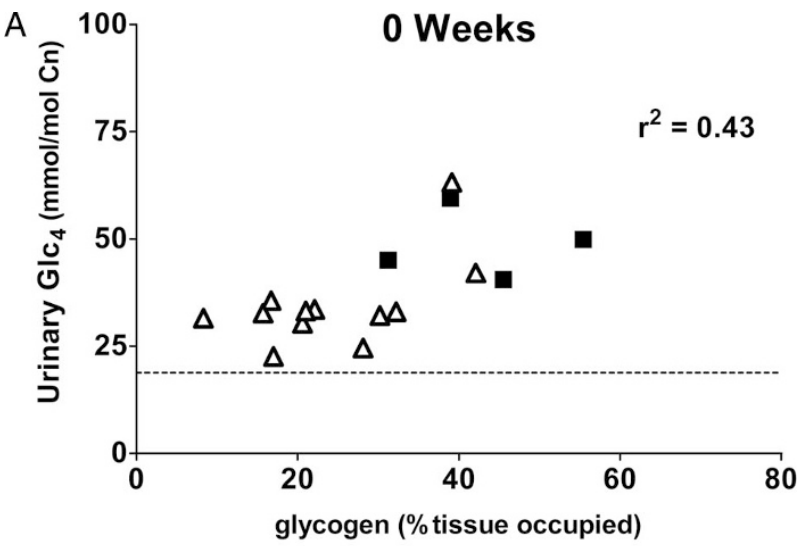

$\mathrm{B}$

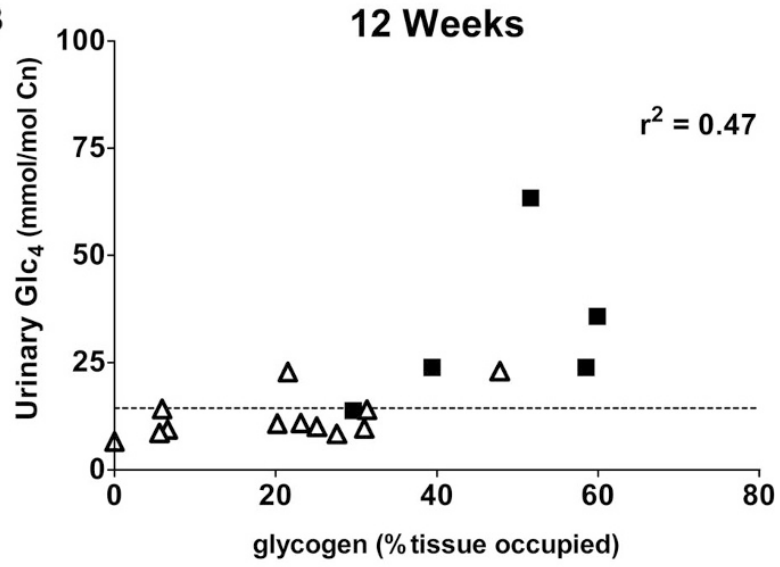

C

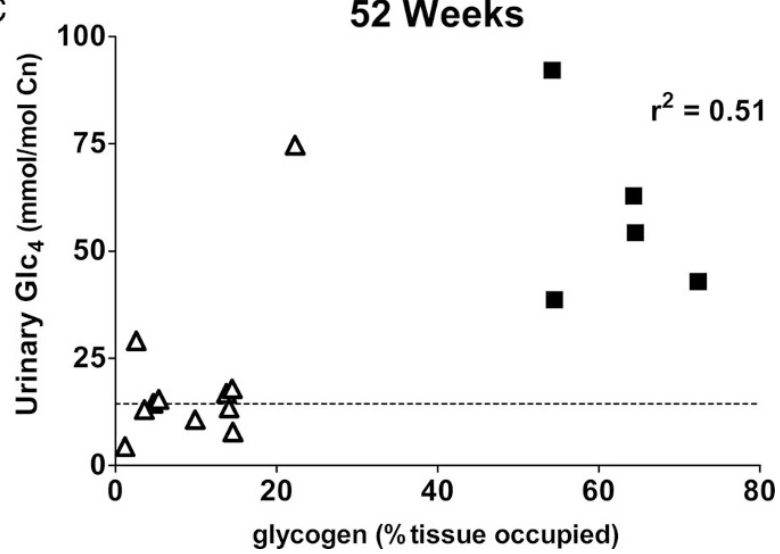

Fig. 1. Correlation of urinary $\mathrm{Glc}_{4}$ with quadriceps glycogen content at: A, Baseline; B, 12 weeks; and C, 52 weeks of ERT. Key: Groups 1 and 2 patients are those who made motor gains during the first 52 weeks of treatment and are represented by open triangles $(\triangle)$. Group 3 patients are those who made minimal or no motor gains during the first 52 weeks of treatment and are represented by closed squares (घ). Note: baseline values were not available for two patients in Group 1, 12 weeks value was not available for one patient in Group 1, and 52 weeks values were not available for one patient in each of Groups 1 and 2 .

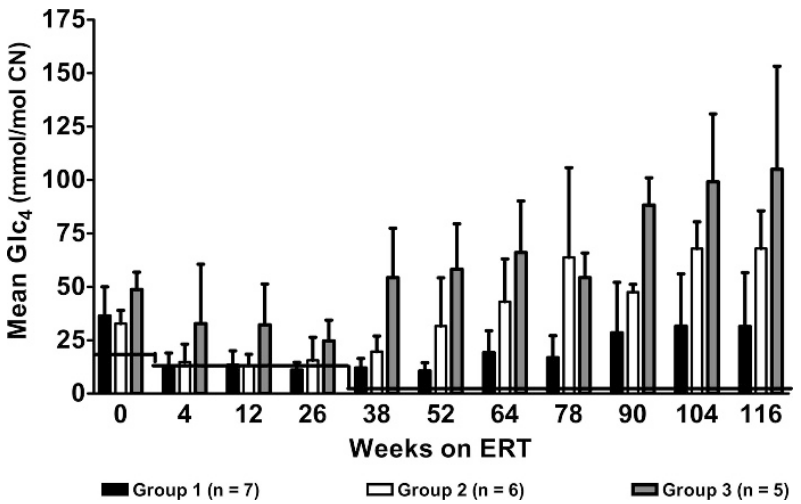

Fig. 2. Trends in mean (SD) urinary $\mathrm{Glc}_{4}$ concentrations with time on ERT for patients in Group $1(n=7)$, Group 2 $(n=6)$, and Group $3(n=5)$. Solid line shows upper limit of the age-matched normal control ranges $(0-6$ months of age: $\leq 19 \mathrm{mmol} / \mathrm{mol}$ creatinine; $6-12$ months age: $\leq 14$ $\mathrm{mmol} / \mathrm{mol}$ creatinine; $\geq 1$ year age: $4.4 \mathrm{mmol} / \mathrm{mol}$ creatinine).

The mean $\mathrm{Glc}_{4}$ levels for the three groups followed distinctive trends. For Group 1 patients $(n=7)$, the biomarker levels remained stable during the first 52 weeks of treatment and corresponded to the minimum value observed at 4 weeks of ERT. The combined group mean $\mathrm{Glc}_{4}$ level for samples collected at 4,12, 26, 38, and 52 weeks ERT was $12 \pm 5$ $\mathrm{mmol} / \mathrm{mol} \mathrm{CN}$ (age-matched controls: $14 \mathrm{mmol} / \mathrm{mol} \mathrm{CN}$ ). Glc levels remained comparatively low (combined mean of $11 \pm 5$ $\mathrm{mmol} / \mathrm{mol} \mathrm{CN}$ ) for samples collected throughout the extension phase of the trial $(64,78,90,104$, and 116 weeks) for three of these patients (F, G, and N). Three other Group 1 patients (B, H, and $\mathrm{O}$ ) showed a modest but significant increase (combined mean of $27 \pm 9 \mathrm{mmol} / \mathrm{mol} \mathrm{CN})$ for the same time period $(P<$ 0.05 ). The seventh patient (I) in Group 1 had rising levels during the second year of treatment that reached $73 \mathrm{mmol} / \mathrm{mol}$ CN by 116 weeks (aged-matched controls: $<4.4$ ). This patient progressed more slowly than the other six patients, and was standing, but not walking at 52 weeks of treatment.

For Group 2 patients $(n=6)$, the minimum level that was observed at 4 weeks of ERT was sustained for 26-64 weeks. The combined mean $\mathrm{Glc}_{4}$ level for samples collected at 4, 12, 26, 38, and 52 weeks ERT was $19 \pm 13 \mathrm{mmol} / \mathrm{mol} \mathrm{CN}$. All patients in this group had rising levels in the extension phase (52-116 weeks of ERT) with a combined group mean $\mathrm{Glc}_{4}$ level of $56 \pm 24 \mathrm{mmol} / \mathrm{mol} \mathrm{CN}$ for this time period.

All Group 3 patients had rising levels of $\mathrm{Glc}_{4}$ during the first year of ERT, after the initial minimum value observed at 4 weeks. Levels continued to rise in the extension phase. Mean values for this group were $42 \pm 22 \mathrm{mmol} / \mathrm{mol} \mathrm{CN}$ for the first 52 weeks and $85 \pm 32 \mathrm{mmol} / \mathrm{mol} \mathrm{CN}$ from $52-142$ weeks and were significantly higher than the mean values for Groups 1 and 2 during both phases $(P<0.05)$.

\section{Markers of skeletal muscle damage and their response to ERT}

The mean CK, AST, and ALT levels from 0-116 weeks of ERT for the three patient groups are presented in Supplemental Digital Content 4, http://links.lww.com/A1144. As observed with $\mathrm{Glc}_{4}$, the mean baseline CK and AST levels were significantly higher $(P<0.05)$ for patients in Group $3(\mathrm{CK}: 1257 \pm$ $747 \mathrm{U} / \mathrm{L}, n=5$; AST: $402 \pm 193 \mathrm{U} / \mathrm{L}, n=5$ ) compared with 
the combined mean for Groups 1 and 2 (CK: $696 \pm 263 \mathrm{U} / \mathrm{L}$, $n=12$, AST: $246 \pm 78 \mathrm{U} / \mathrm{L}, n=11)$. There was no significant difference in baseline ALT levels. The mean CK, AST, and ALT values remained elevated above the control range throughout the study for all groups. This is in contrast to $\mathrm{Glc}_{4}$ levels, which normalized 4 weeks after initiation of ERT for Groups 1 and 2. As with $\mathrm{Glc}_{4}$, the CK, AST, and ALT values were higher for Group 3 during the first 52 weeks of ERT, but unlike $\mathrm{Glc}_{4}$, the mean values of these biomarkers did not increase over time. AST showed the best discrimination between groups with trends similar to $\mathrm{Glc}_{4}$, whereas CK and ALT levels appeared to fluctuate and differences between groups were smaller.

\section{DISCUSSION}

Patients with infantile-onset Pompe disease on ERT show considerable variation in their clinical response to treatment. ${ }^{2-8}$ Although the majority of patients have marked improvements in the cardiac hypertrophy associated with this disorder, significant gains in motor function have only been observed for a subset of patients. To understand this variability, it is important to monitor the response of target tissues to therapy. Histologic and biochemical studies on the glycogen content and tissue integrity of quadriceps biopsies have provided valuable insights on the correlation of disease burden with the response to treatment. ${ }^{4,9}$ However, this invasive approach cannot be used routinely in the management of patients on therapy. The results from this study showed a strong correlation between urinary $\mathrm{Glc}_{4}$ and skeletal muscle glycogen at three different time points. We have previously observed a statistically significant correlation at 0,12 , and 52 weeks between urinary Glc $_{4}$ levels and quadriceps glycogen content by histomorphometric analysis for patients enrolled in the Phase II trial reported by Kishnani et al. ${ }^{3}$ (unpublished data).

Baseline levels of urinary $\mathrm{Glc}_{4}$ and muscle glycogen correlated with the response of skeletal muscle to treatment over the first 52 weeks. The five patients who did not make motor gains during this time had significantly higher baseline glycogen and $\mathrm{Glc}_{4}$ levels. Histologic studies from the previous Phase II trial demonstrated a correlation between the extent of muscle disease at baseline and the clinical response. ${ }^{9}$

Our results from earlier clinical trials of ERT in infantile Pompe disease indicated that urinary $\mathrm{Glc}_{4}$ may have predictive value as a biomarker. ${ }^{13}$ The results from this more extensive clinical trial support our previous observations. A failure of $\mathrm{Glc}_{4}$ levels to normalize within the first few weeks of treatment correlated with minimal gains in motor function and a poor prognosis, as observed for patients in Group 3. Conversely, a rapid decrease in $\mathrm{Glc}_{4}$ levels after 4 weeks of therapy and maintenance of low levels over the course of treatment were associated with a favorable outcome, as observed for Group 1 patients. A subset of patients (Group 2) with an initial favorable response suffered a clinical decline, or made no further progress in the second to third years of treatment. This decline coincided with or was preceded by a rise in $\mathrm{Glc}_{4}$ levels from its minimum value. The reasons for the clinical decline of patients in Group 2 and the minimal motor response in Group 3 patients are not fully understood. As previously reported, cross-reacting immunologic material (CRIM)-negative status is a poor prognostic factor. ${ }^{4,17}$ CRIM-negative patients have high antibody titers against the infused enzyme that may interfere with delivery of the infused enzyme to target tissues. ${ }^{2-4,17}$ Two patients in Group 2 ( $\mathrm{C}$ and $\mathrm{L}$ ) and two patients in Group 3 ( $\mathrm{P}$ and $\mathrm{R}$ ) were CRIM negative. Patient $\mathrm{R}$ never made motor gains despite having low $\mathrm{Glc}_{4}$ levels for the first 6 months of treatment. However, the glycogen in muscle biopsies was elevated for this patient (see
Supplemental Digital Content 3, http://links.lww.com/A1143). The reason for this discrepancy is unclear.

Three patients in Group 1 experienced a mild increase in $\mathrm{Glc}_{4}$ by the end of the extension phase of the trial, compared with levels observed over the first year of treatment. If $\mathrm{Glc}_{4}$ is a biomarker of glycogen accumulation, as our correlation data suggest, these mild elevations may indicate a reaccumulation of glycogen in existing muscle, or may be related to an increase in muscle mass, and/or increased ambulation with consequential muscle damage. The trend in $\mathrm{Glc}_{4}$ levels was clearly different for Patient I compared with the other six patients in Group 1. This patient made slower gains in motor function and demonstrated markedly increased levels of $\mathrm{Glc}_{4}$ by end of the study. This patient is reportedly doing well, although walks with difficulty, has tightness of the ankle joints and has low percentile ranks on all subcategories of the Bruininks-Oseretsky Test of Motor Proficiency, except for fine motor skills (Dr. Brian Tsai, Division of Genetics and Metabolism, Department of Pediatrics, Chi Mei Foundation Hospital, Taiwan personal communication, 2009). It is possible that this patient has variable glycogen accumulation in different muscle groups, with sparing of the cardiac and respiratory muscles allowing prolonged survival. Long-term monitoring will be required to understand the correlation of these increases with the clinical outcome.

A decrease in $\mathrm{Glc}_{4}$ as early as 4 weeks on ERT was observed in all patients for whom data were available, regardless of the clinical outcome. This decrease may represent clearance of glycogen, and perhaps the biomarker itself, from tissues that are more easily accessible to the enzyme, such as the vascular endothelium, and/or more efficiently take up the enzyme, such as cardiac muscle. Additionally, this observation may indicate the efficacy of ERT in the first few weeks of treatment before the development of high titers of anti-rhGAA immunoglobulin $\mathrm{G}$ experienced by some patients.

The conventional plasma markers of muscle cell damage, $\mathrm{CK}, \mathrm{AST}$, and ALT, were monitored at the same time points in the trial as $\mathrm{Glc}_{4}$. These enzyme markers were more elevated in the patients with the poorest response, suggesting greater muscle damage and hence a more advanced disease state. However, none of these enzyme markers showed as good a correlation with the motor function response, as $\mathrm{Glc}_{4}$. AST and ALT are not specific to muscle and can also be derived from the liver. It is not possible to determine the proportion of plasma AST and ALT that is derived from muscle, making interpretation of these levels more complex. The value of $\mathrm{Glc}_{4}$ as a biomarker for monitoring response is its presumed derivation from glycogen released from damage muscle. This hypothesis is supported by the statistically significant correlation of $\mathrm{Glc}_{4}$ levels with measurements of glycogen storage in this study and by the previous work of others. ${ }^{11,12}$ The results from this study support the utility of monitoring urinary $\mathrm{Glc}_{4}$ levels in patients with infantile-onset Pompe Disease receiving ERT.

\section{ACKNOWLEDGMENTS}

Funding for this research was provided by Genzyme Corporation, from whom permission was granted for inclusion of clinical and biochemical data from the trial. The authors thank the patients and their families, and all investigators involved in the clinical trials of rhGAA. They also thank Dr. Joan Keutzer for useful discussions and ongoing support and encouragement for this research, Dr. Horacio Plotkin for feedback on this manuscript, Jenna Hollenstein, MS, ELS, of Genzyme Corporation for editorial assistance, the team at Genzyme Corporation 
involved in these clinical trials and Dr. Brian Tsai for updated clinical information.

\section{REFERENCES}

1. Hirschhorn R, Reuser AJ. Glycogen storage disease type II: acid $\alpha$-glucosidase (acid maltase) deficiency. In: Scriver CR, Beaudet AL, Sly WS, Valle $\mathrm{D}$, editors. The metabolic and molecular bases of inherited disease, 8th ed. New York, NY: McGraw-Hill, 2001:3389-3420.

2. Amalfitano A, Bengur AR, Morse RP, et al. Recombinant human acid alpha-glucosidase enzyme therapy for infantile glycogen storage disease type II: results of a phase I/II clinical trial. Genet Med 2001;3:132-138.

3. Kishnani PS, Nicolino M, Voit T, et al. Chinese hamster ovary cell-derived recombinant human acid alpha-glucosidase in infantile-onset Pompe disease. $J$ Pediatr 2006;149:89-97.

4. Kishnani PS, Corzo D, Nicolino M, et al. Recombinant human acid $\alpha$-glucosidase: major clinical benefits in infantile-onset Pompe disease. Neurology 2007;68:99-109. Erratum in Neurology 2008;71:1748.

5. Van den Hout JM, Reuser AJ, de Klerk JB, Arts WF, Smeitink JA, Van der Ploeg AT. Enzyme therapy for Pompe disease with recombinant human $\alpha$-glucosidase from rabbit milk. J Inherit Metab Dis 2001;24:266-274.

6. Van den Hout JM, Kamphoven JH, Winkel LP, et al. Long term intravenous treatment of Pompe disease with recombinant human $\alpha$-glucosidase from milk. Pediatrics 2004;113:e448-e457.

7. Kling L, Straub V, Neudorf U, et al. Safety and efficacy of recombinant acid alpha-glucosidase (rhGAA) in patients with classical infantile Pompe disease: results of a phase II clinical trial. Neuromuscul Disord 2005;15:24-31

8. Rossi M, Parenti G, Della Casa R, et al. Long-term enzyme replacement therapy for Pompe disease with recombinant human alpha-glucosidase derived from Chinese hamster ovary cells. J Child Neurol 2007;22:565-573.

9. Thurberg BL, Lynch Maloney C, Vaccaro C, et al. Characterization of preand post-treatment pathology after enzyme replacement for Pompe disease. Lab Invest 2006;86:1208-1220.

10. Kishnani PS, Steiner RD, Bali D, et al. Pompe disease diagnosis and management guideline. Genet Med 2006;8:267-288.

11. Ugorski M, Seder A, Lundblad A, Zopf D. Studies on the metabolic origin of a glucose-containing tetrasaccharide in human urine. J Exp Pathol 1983; $1: 27-38$.

12. Kumlien J, Chester MA, Lindberg BS, Pizzo P, Zopf D, Lundblad A. Urinary excretion of a glucose-containing tetrasaccharide. A parameter for increased degradation of glycogen. Clin Chim Acta 1988;176:39-48.

13. An Y, Young SP, Kishnani PS, et al. Glucose tetrasaccharide as a biomarker for monitoring the therapeutic response to enzyme replacement therapy for Pompe disease. Mol Genet Metab 2005;85:247-254.

14. Young SP, Stevens RD, An Y, Chen YT, Millington DS. Analysis of a glucose tetrasaccharide elevated in Pompe disease by stable isotope dilutionelectrospray tandem mass spectrometry. Anal Biochem 2003;316:175-180.

15. McVie-Wylie AJ, Lee KL, Qiu H, et al. Biochemical and pharmacological characterization of different recombinant acid alpha-glucosidase preparations evaluated for the treatment of Pompe disease. Mol Genet Metab 2008;94:448-455.

16. Lynch CM, Johnson J, Vaccaro C, Thurberg BL. High resolution light microscopy (HRLM) and digital analysis of Pompe disease pathology. J Histochem Cytochem 2005;53:63-73.

17. Mendelsohn NJ, Messinger YH, Rosenberg AS, Kishnani PS. Elimination of antibodies to recombinant enzyme in Pompe disease. $N$ Engl J Med 2009; 360:194-195. 